\title{
6 Perspectives for Interreligious Education
}

The evaluation of the empirical material revealed different areas of tension in two different settings: the school and the university. Three areas of conflict could be identified and examined in detail in both settings.

The first area of conflict in the school setting, referred to as '(religious) group dynamics', covers the tense implications of asymmetric initial conditions, religious boundaries, and the formation of inter- or intrareligious subgroups. The second area of tension 'themes and didactics', focuses on the question of the themes to be dealt with and their preparation and reflects challenges and difficulties in the area of didactics and methodology. It also looks at what is possible in settings of interreligious teaching and learning. At the heart of the third area of conflict in the school setting is the theme of 'identity and confessionality'. Among other things, the boundaries of interreligious collaboration in educational contexts are negotiated, and the extent to which encounters with the religious other are considered appropriate or counterproductive for the pupils' identity formation is explored.

The university setting revealed three areas of tension as well. The first source of conflict - 'planning, approaches, and expectations' - focuses on the conceptualisation and objectives of the university course and reveals different and sometimes contradictory expectations and desires in an interreligious setting. The second area of conflict concerns the 'process, communication, and group dynamics' and shows explicit tensions between course teachers as well as between course teachers and students, which were ignited by communication dynamics, competences and responsibilities, or by leadership issues. The third area of conflict focuses on the 'conflict about "ideal" religious education and recognition'. Here, discrepancies and divergences between the participants were expressed regarding the questions of what constitutes successful religious education, what tasks a religion teacher has to fulfil, and which expectations of the school community need to be met.

In the overview of the empirical data, themes that contain conflict potential emerge. They overlap to some extent in the settings, taking up aspects of the sources of conflict and bringing them to an abstract, general level. For the following analysis, seven complex themes were selected:

- interaction in interreligious settings

- teaching interreligious processes

- didactic and methodological approaches

- finding and developing themes

- interreligious learning in a confessional context 
- the significance of the religious

- binary spaces - Third Spaces

- conflict and communication.

To make the results accessible to as many people as possible who are involved in interreligious work in education, the following discussion largely dispenses with the concrete contexts of the study, school, and university. The focus is on the question of the central fields of conflict in interreligious educational work.

\section{Interaction in Interreligious Settings}

A challenge and a possible area of conflict in interreligious contexts and mixed religious groups is group dynamics.

- The composition of an interreligious learning group has a special impact on the possible conflict potential in that group. Depending on the context, the proportion of members from individual religious communities cannot always be controlled. The composition can lead to unbalanced and asymmetric group relationships. The challenge consists in taking these circumstances into account in the didactic and methodological conceptualisation of education. Didactics should be understood in a holistic and multi-perspectival sense, in which the individual/biographical approaches are taken into account as well as the dynamics of the group, the context or facts and content.

- In addition to the composition, the differentiation in the group is an important factor. The intrareligious in-group formations are particularly relevant. In-group formations can create a dynamic of exclusion. The resultant exclusion of individual group members from participation in the overall process would jeopardise the aim of the educational processes. Our research shows that the instructors of educational processes have a significant influence on the formation of (religious) subgroups. Both the interactions and role models within these subgroups as well as interactions with or from the group members can strengthen or decrease them - this becomes clear, for example, in team teaching. At the same time, we were able to prove that, although the formation of subgroups occurs along religious boundaries, the motivation here is not necessarily religiously based. Factors such as personal competences and characteristics as well as the question of whether (some) participants of the learning group already know each other in advance and thus have well-established communication habits play a decisive role here.

- In situations where asymmetry is inevitable (e.g., due to the general conditions), the balance in group dynamics is served if the participants, especially 
those who are in the minority position, compensate for this through flexibility, activity, and a willingness to communicate. But this is associated with an effect typical of heterogeneous groups that can increase the asymmetry and power relations: compared to the participants in the majority position, the participants in the minority group must invest extra effort in this communication dynamic in advance. This can be perceived as a burdensome obligation to contribute to successful communication.

- A particularly delicate communication dynamic becomes visible in connection with the actors in interreligious learning groups. In the case of mixed religious teaching, this can form a 'triangular communication': both the mixed religious participant group and the mixed religious teacher group are intra- and interreligiously oriented. The individual actors or groups do not necessarily act in harmony with each other but - depending on the combination that is formed - sometimes heterogeneously or against each other. This results again and again in a triangular constellation in which two actors communicate without involving the third party or parties.

\section{Teaching Interreligious Processes}

As already became clear in the previous section, the mixed religious teaching is very prominent with regard to conflict potential in educational processes. The understanding of teaching in a team or team teaching and how to deal with it are central concerns here. Teaching styles and personality traits have great influence.

- Theological, didactic, methodological, and personal views and approaches play a significant role in the emergence of conflict. These views usually have a pre-reflective character, usually encounter each other directly, create incompatibilities and contradictions and implicitly control the actions of the persons involved. Based on this conflict potential, it becomes clear what significance the (self-)explication or (self-) explanation of subjective concepts should have individually and collectively in the training and further education and professional development of instructors. This also applies to individual understandings of roles and tasks that are not discussed.

- Leadership or team teaching entails a new constellation. It involves more than merely 'adding' two or more teachers. Even previously experienced instructors can encounter a new teaching situation/team teaching situation in which previously clearly defined competences or responsibilities have to be clarified anew.

- Asymmetries can also arise within the teaching team concerning evaluations and assessments (competences, approaches, responsibilities, etc.). Against 
this background, dominance/marginalisation constellations can emerge that often correspond to or are strengthened by the societal relations between majority and minority groups. Sometimes, however, the majority and minority groups, or the established and outsider relations in such settings can also move in the opposite direction from societal conditions.

- The mutual evaluation of the persons involved in teaching and/or team teaching also contains conflict potential. This assessment can relate to theological, didactic, or methodological approaches, teaching and learning practices and action strategies as well as personality traits. Comparative dynamics, mimetic and competitive relationships play a central role here. Education and continuing education and development in teaching/team teaching can make a significant contribution as well to improving the individual, social, and contextual conditions for joint teaching of educational processes. This can be done by strengthening personality and role awareness as well as by paying attention to the shared task.

- It also became clear that the teachers in team teaching should be guided individually and in teams by their supervisors or project managers. The subject of such guidance can be both self-reflection and reflection on patterns of communication and action. Moreover, meetings in peer groups and the practice of mutual feedback are of central importance. In addition, sensitivity to the perception of oneself and the other as well as identification and mirror phenomena are central. These can be traced back to the fact that people can simulate and anticipate the emotions and actions of others.

\section{Didactical and Methodological Approaches}

The present empirical study clearly shows that, for both the course instructors' team or team teaching and among the participants, the question of the quality of the teaching and learning approaches or - as far as the context of the school is concerned - the quality of religious education is present and contains far-reaching conflict potential. The probability of and the nature of the manifestation of conflicts or their intensity obviously depends on the fields of interreligious education. Thus, it can be assumed that conflict potential in settings of adult education, community work, or in volunteer groups is lower than in compulsory groups in school or - in a qualified sense - university.

- From the analysis of the empirical results, it became clear that, in interreligious learning settings, especially in fields of action at schools, conflict potential can develop around the conception of didactics. Approaches that are more focused on content and have a more instructionalist emphasis are op- 
posed to those that focus on participant and context orientation as well as creativity. Both concepts are advocated with normative claims.

- In some contexts, third parties or groups of people with their ideas and demands have a (usually indirect) influence on the instructors and thus also on the teacher's didactic and methodological design of the teaching and learning processes.

- In the debate on didactic approaches, religious authenticity is sometimes also mentioned. From the perspective of instructors or others, there is a normatively constituted connection between the respective religion and the nature of the didactical approaches.

- Similar normative connections are sometimes also noted regarding the choice of methods, which means that in the interreligious conceptualisation of teaching and learning processes, sensitivity to the different approaches to the choice of methods is central.

\section{Finding and Developing Themes}

Finding and developing themes in an interreligious context is central to interreligious education. The choice of theme is considered a particularly sensitive aspect.

- The widely applied strategy for finding themes is based on the criterion of so-called neutrality. This generally refers to anthropological or social themes or themes on Islam and Christianity that allow an external perspective, sometimes comparative themes as well. This criterion is often based on a narrow conception of religion or theology. Themes that are more broadly defined are sometimes not recognised and identified as religious or theological.

- In general, it was found that the process of finding themes is difficult and requires the negotiation of topics and content that are suitable for collaboration (team teaching). It also became clear that the instructors of interreligious groups need to be guided in finding themes.

- Furthermore, it became clear that a shared framework - a kind of shared way of life and encounter - is needed in which all actors are involved and within which understanding is possible. A didactical approach is also needed on whose basis themes can be developed together and competencies formulated - for example through the didactic analysis on and reflection on context, group, one's own approaches and content. In addition, the didactic understanding of the methodological and content-related structuring of the themes is also central to interreligious education. 
- Another important aspect that emerged from the empirical study is the importance of working on concepts. Here, it is particularly important to keep in mind that the same concepts can have different meanings in the respective religious traditions. This can often lead to misunderstandings because the same or similar concepts are interpreted differently. Therefore, the explication and differentiation of the concepts is essential. Only in this way can interreligious education be made productive. Defining concepts will also make it possible to prevent unnecessary difficulties and misunderstandings by defining concepts.

\section{Interreligious Learning in a Confessional Context}

- Another thematic area that is central to interreligious work and at the same time susceptible to conflict unfolds around the examination of the question of what interreligious learning means in a confessional context. This study revealed that teachers faced difficulties with regard to the interreligious division of labour in the areas of 'religiosity/spirituality', 'beliefs' and 'religious experience'. There was a clear position here on both sides that the treatment of the spirituality, beliefs, or creed of one's own religion - in a confessional setting - was reserved exclusively for members of one's own religion/in-group.

- This attitude was reinforced by the general ecclesiastical and confessional conditions. The positive effects of the interreligious encounters were strongly identified by the instructors in their own confessional area, especially in the sense of enriching the Catholic denomination.

- At the same time, the learners were characterised by an openness to interreligious encounters. They showed an interest in people of other faiths and indicated that they can classify the encounter with a religious other who is different from them religiously accordingly.

- New perspectives regarding identity models can be derived from this empirical study. Early interreligious encounters can make a positive contribution to the development of religious identity. Prejudices and the formation of stereotypes are also counteracted by encounters with people of other faiths. In general, it can be stated that interreligious collaboration and encounters within the framework of denominational religious education have both a positive effect on one's own fears and reservations regarding one's religious other and those of other faiths, as well as a preventive effect on the possible resentment of those who adhere to a different religion. 


\section{The Significance of the Religious}

Interesting perspectives came to light regarding the visibility or invisibility of the religious.

- $\quad$ The interviews made it clear that religious education (in school) is perceived as an important factor for the religious socialisation of children and has thus gained social significance in the eyes of teachers or educators.

- Religious education is seen by all participants as very important and central to the identity development of children.

- Differences arise as to whether the encounter with the religious other is considered constitutive or destabilising for the religious socialisation of the pupils. For example, some parents vehemently opposed interreligious collaboration because they saw the children's development of religious identity as endangered.

\section{Binary Spaces - Third Spaces}

Another complex of topics concerns the spaces and framework conditions of interreligious educational processes.

- One's own religious space is thus initially perceived as the familiar space and the space of the other as strange. This can create a binary structure in which alternatives are construed in a dualistic sense as either-or.

- Spaces can also have asymmetrical conditions. The space of the religious other is perceived as a challenge since there is little knowledge about the content and practice of the other religion and neither the points of contact nor the boundaries are known.

- In some situations where the interreligious relationship tends towards binary spaces or dual concepts or develops in the direction of dualistic either-or specifications - be it in private relationships or in public, religious community or educational contexts - opening up to other possibilities is necessary. This can mean opening up other spaces ('Third Spaces') ${ }^{1}$. An example of the development of other ('third') possibilities can be found in rituals that mixed confessional or mixed religious couples or families can perform. To avoid being fixed on the customs and rituals of a single religion, new ('third') forms develop again and again in these relationships and families that cannot be clearly assigned to one religion or the other. In such a space of further possibilities, the school or - as in the case of the establishment of the Islam-

1 See chapter $\mathbf{1}$, footnote 32. 
ic religious education programme - the university can represent other possibilities.

\section{Conflict and Communication}

Conflicts can arise in interreligious collaboration in school contexts among the different groups of people involved (parents, school directors, colleagues).

- $\quad$ The strategy of open communication with all parties involved has proven its worth in preventing possible areas of tension.

- When planning interreligious projects, it must be kept in mind that concrete information is being passed on to those involved in the run-up to implementation.

- This anticipatory communication should involve not only adults but also the pupils so as to create the conditions for them to adequately reflect on interreligious experiences.

- At the same time, we were able to point out the importance of exposing power asymmetries that manifest themselves in interreligious education. To be able to plan lessons on an equal footing, it is important to identify these asymmetries, name them, and counteract them. Since Islamic religious education in Austria is a relatively young academic field, interreligious educational collaboration faces numerous challenges, as this study has demonstrated. Religious education or religion also reflects social dynamics here.

If we look back on this study about conflicts and conflict potential in interreligious educational processes, the intensity and differentiation in this research process becomes clear. The work was carried out strictly within an interreligious research team. The empirical data have been subjected to this dual perspective in numerous discussions. With respect to content, many areas of tension have been demonstrated, patterns of thought and action have been identified, perspectives have been related to each other, and effects have been named. A wide field with an immediate need for action regarding education has opened up.

We consider the need to continue interreligious teaching and research and, in particular, to deepen it to be a central conclusion from our findings. Thus, the next steps will be dedicated to basic research. A review and systematisation of the existing interreligious theories and concepts is urgent in view of the increase and importance of interreligious collaboration in research, teaching and practice at various locations. Given this basis, the conceptualisation and development of interreligious educational processes should be carried out in both theory and practice - especially in the areas of religious education and school culture as well as in teacher training and the further education of educational leaders. 